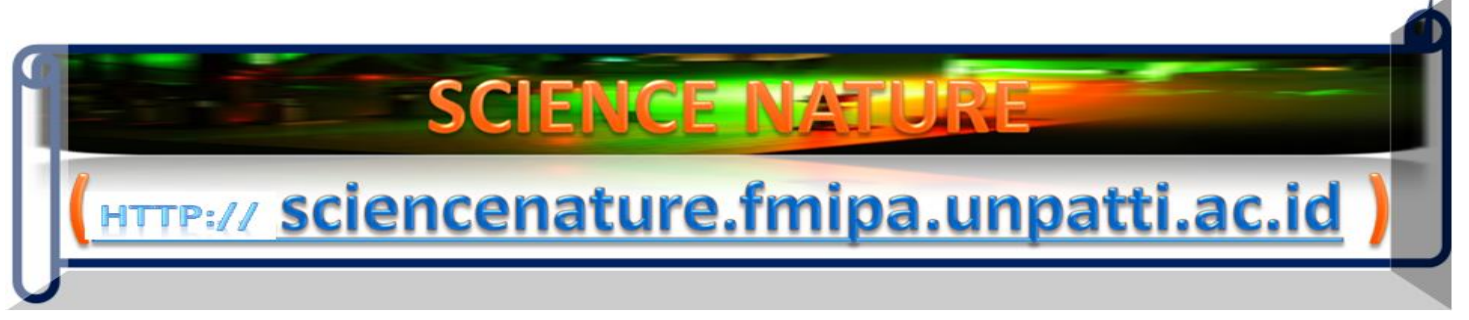

Science Nature 3(2), pp257-274 (2020)

e-ISSN: 2654-6264

DOI: https://doi.org/10.30598/SNVol3Iss2pp257-274year2020

\title{
Stamec-Gravitism: A Simple Theoretical Study to Inspire a Prototype Fabrication for Mobile Perpetual Electricity Generator
}

\author{
Yosua Pratama Iswahyudi ${ }^{1-4}$ and Hendry Izaac Elim ${ }^{1-6, O}$ \\ ${ }^{I}$ Theoretical Physics Laboratory (TP Lab.), Department of Physics, FMIPA, UNPATTI, \\ Jl. Ir. M. Putuhena, Poka, Ambon, Indonesia 97233 \\ ${ }^{2}$ Nanomaterials for Photonics Nanotechnology Laboratory (N4PN Lab.), Department of \\ Physics, Faculty of Mathematics and Natural Sciences (FMIPA), Pattimura University (UNPATTI), \\ Jl. Ir. M. Putuhena, Poka, Ambon, Indonesia 97233 \\ ${ }^{3}$ Nanotechnology Research Center and Innovative Creation (PPNRI-LPPM), and Nanomedicine Garden in \\ Research and Society Center of Pattimura University, UNPATTI, \\ Jl. Mr. CHR. Soplanit, Rumah Tiga, Ambon, Indonesia 97234 \\ ${ }^{4}$ Teaching Laboratory of Electronics and Instrumentation, Physics Department, \\ Pattimura University, Ambon, Maluku, Indonesia 97233 \\ ${ }^{5}$ Ambon Academy of Science and Arts (A-ASA), Kapitan Permata Street, Ambon Island, Indonesia. \\ ${ }^{6}$ Multidisciplinary Research Center of Excellence (MrCE), Integrated Laboratory (i-LAB), UNPATTI, Jl. Chr. \\ Soplanit, RumahTiga, Ambon, Indonesia 97234
}

$\begin{array}{ll}\text { Received } & : 1^{\text {st }} \text { May } 2020 \\ \text { Revised } & : 2^{\text {nd }} \text { June 2020 } \\ \text { Published } & : 14^{\text {th }} \text { June } 2020\end{array}$

Copyright @ All rights are reserved by Yosua Pratama Iswahyudi and Hendry Izaac Elim.

Corresponding author: "Email: : hendryelim@gmail.com; hendry.elim@staff.unpatti.ac.id 


\section{Abstract}

This novel research presents a theoretical work and its simple simulation as a breakthrough way to derive a mobile electricity apparatus with the weight of $\sim 5 \mathrm{~kg}$ generated by an eternal gravity force on earth. The theoretical research was extracted in such a guide simply by incorporating statistical mechanics, classical mechanics and basic theory of electricity and magnetism. In the above-mentioned smart calculation, ones obtain the definition of a constant temperature particularly in isothermal enviromental nature. Furthermore, by solving the whole basic physics relationship with gravity source of power, the electrical energy formula was excerpted with the simplification through a Stamec-Gravitism: a simple theoretical study to inspire a prototype fabrication for mobile perpetual electricity generator. Furthermore, the work is sustained with its simulation results to find out the working physical parameters for normal use of alternating current (AC) electricity system with frequency of $50 \mathrm{~Hz}$ and electrical power of $\sim 100$ Watt for each proposed apparatus. This research suggests a bright future for the light mobile electricity generator for the needy and the poor in every different nations and tribes consisted of thousands of small islands because it does not need battery storage to work in any different conditions and weather so that such novel work can contribute in a large scale to mitigate natural disasters on earth by implementing it in all human being daily activities based energy uses.

Keywords: Theoretical study, Stamec-Gravitism, Mobile Perpetual, Electricity Generator.

\section{NEW INVENTION}

\section{Introduction}

Integrated works using diversity philosophy [1] in creativities based on creative and innovative critical thinking and intelligent works [1-19] according to smart development of renewable energies have become an
The invented contribution: Novel Mobile Perpetual Electricity Generator using gravity force.

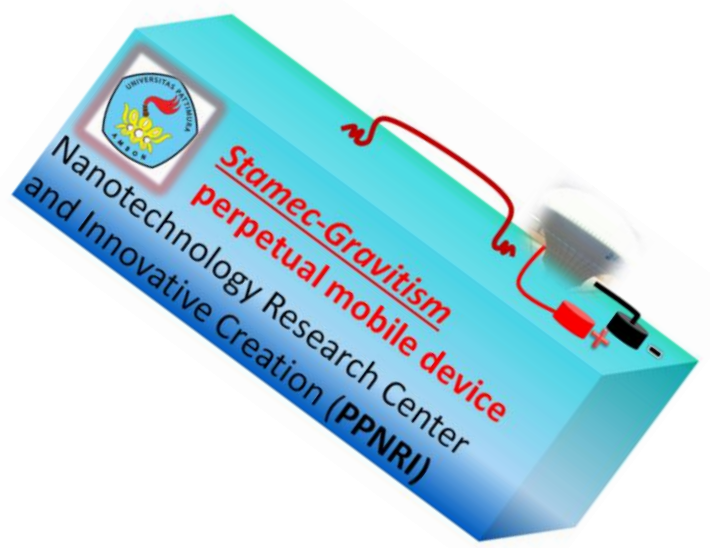

important collaborative factors to solve the energy crisis associated with environmental problems due to the exponential growth of human being up to $\sim 8$ billion people on earth particularly in the European Union, Russia, United States, China, Indonesia, Australia, India, and Brazil. Moreover, a protective ecology exploitation sustained by 
proper policies and its strategies policies generated and observed by relevant statistical departments and authoritative institutions in a country with good governance could enhance energy efficiency and trim down greenhouse gas emissions mainly from coal, natural gas and oil as well as nuclear energy in order to tackle the world wide global warming [20-51].

Recently, the principal types of renewable energy sources adapted to different stages of brilliant technology development which are free of labors consist of at least the following 7 energies of (i) wind, (ii) solar, (iii) biomass, (iv) geothermal, (v) ocean, (vi) hydropower (water), and (vii) hydrogen, respectively. These all sources of green energy needs excellence storage device like mobile battery with a very effective charge time and strong ability in different weather and conditions [52-57]. Through such implementation of related renewable energy technologies, the reduction of carbon emissions, the share of electricity in daily energy consumption and energy implementation efficiency to society can be dramatically improved in many divergent ways. For example: the use of sea surface current $\sim 1.0 \mathrm{~m}$ under the ocean surface called as tidal wave has key advantage as a renewable energy source because of the tidal cycles are predictable, unlike conventional wind and solar energy, which are highly susceptible to weather fluctuations. However, everything in the world may be exponentially distorted due to a complex broken environment system closely linked with huge growing of human being industrial companies, business traffics, residential apartments, electrical mobile power generators, and vehicles traffic activities due to the exponential increase of people in every different countries so that the price of free labor renewable energies become expensive. In addition, graviticity is a kind of electrical generator working based on the vertical move of a very heavy load in about $150 \mathrm{~m}$ distant deep underground to obtain a large electrical power ( MW). Figure 1 describes a general picture of renewable energies and graviticity (one of gravity technology) according to their nature in universe. On the other hand, Fig. 2 shows the origin of gravity in our expanded universe. The wavelength of gravity is close to infinite or much longer than that in electromagnetic field so that there is no radiation at all. Such type of wave has very weak interaction in comparison with electromagnetic interaction in nature. In addition, gravity has no different in both quantum size such as in atom or nuclear and bulk/ macroscopic size of matters [51]. Furthermore, the existence of gravity has been very precisely measured using a simple pendulum system and interferometry Michelson [7]. The integrated physical parameters that mostly influence gravity are temperature $(T)$, pressure $(p)$ and the interaction speed $\left(v_{i}\right)$ of two related objects in a system inside universe before the big bang (Plack time of $\sim 10^{-43} \mathrm{~s}$ ) or in the physical system of strings interaction according to M-theory.

In present distinguished paper, a simple theoretical study based on a derivation of theoretical understanding depicting in Fig. 3 by incorporating three important classical physics such as statistical mechanics (Stat.Mech.) as a starting point consisted of mechanics and thermodynamics, gravity, and electromagnetism in an integrated mobile system is proposed for the first time to 
inspire a prototype fabrication for mobile perpetual electricity generator. The aim of the use of gravity energy is solely because of the consideration on its eternal presence in universe with its super giant in super weak radiation, free in eternal nature, and no harmful radiation at all. The theoretical physics works with the output name of such interesting mobile energy device were Stamec-Gravitism extracted using a deep understanding of the collaboration among Stat. Mech., classical rotation mechanics linked with gravity, and electromagnetism system associated with the former two. Such novel invention is very different from graviticity which was generated using a steady state of vertical heavy system machine in a deep $\sim 150 \mathrm{~m}$ underground. In addition, it is free of the use in battery storage to work in any different circumstances. This research suggests a bright future for the light mobile electricity generator for the needy and the poor in every different nations and tribes consisted of thousands of small islands because such novel work can contribute in a large scale impact to mitigate natural disasters like floods, hurricane, tornado, earthquakes, unstable ocean impacts, and so forth on earth generated by the complicated problems of daily use energies by human being as well as their culture and mental problems [58-60].

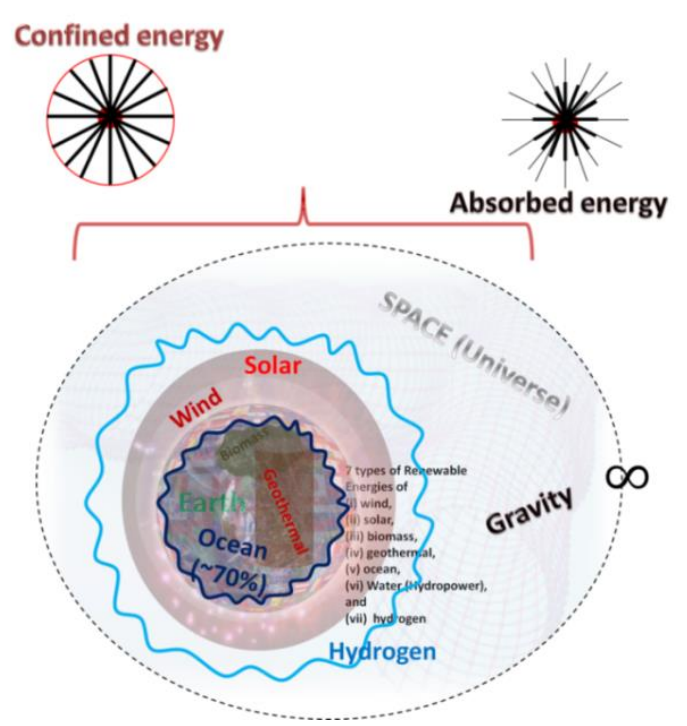

Figure 1. Flowchart of renewable energies and graviticity system: free labor electrical energy source with their interconnections. 


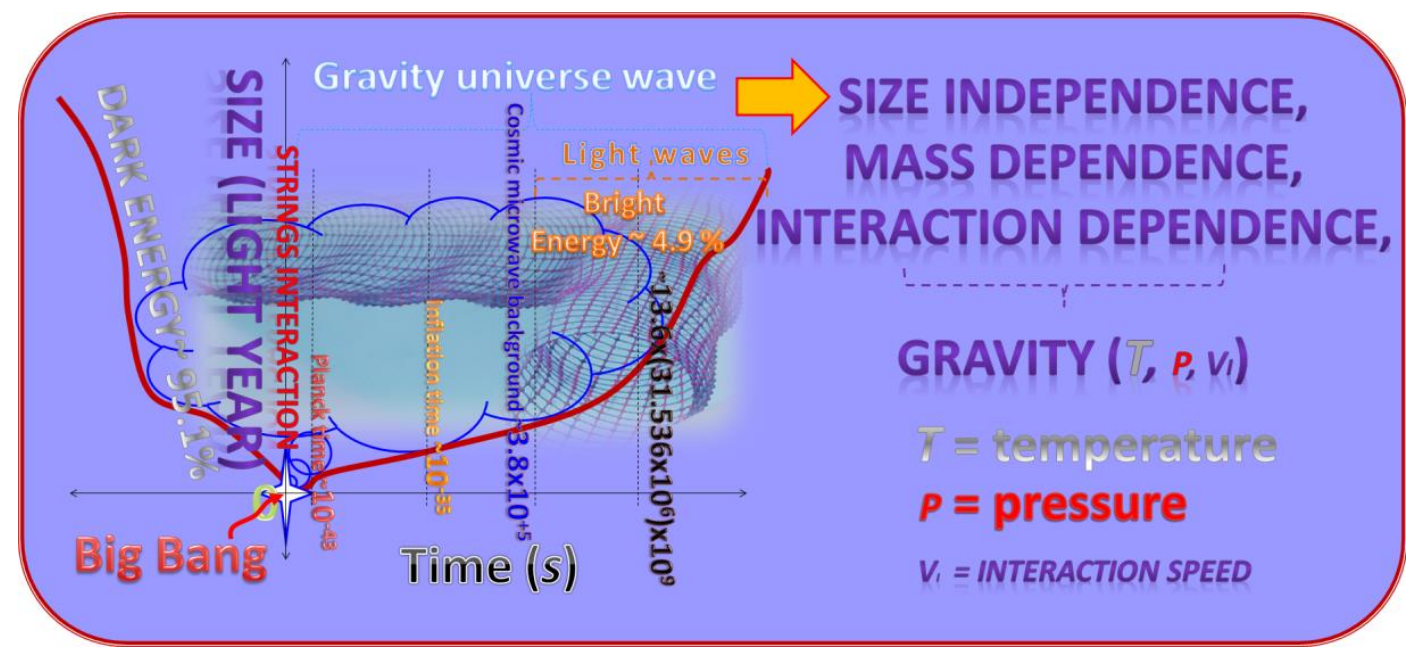

Figure 2. Illustration of the origin of gravity in our

expanded universe extracted from the whole

physical parameters in nature including the

presence of dark matters before the big bang.

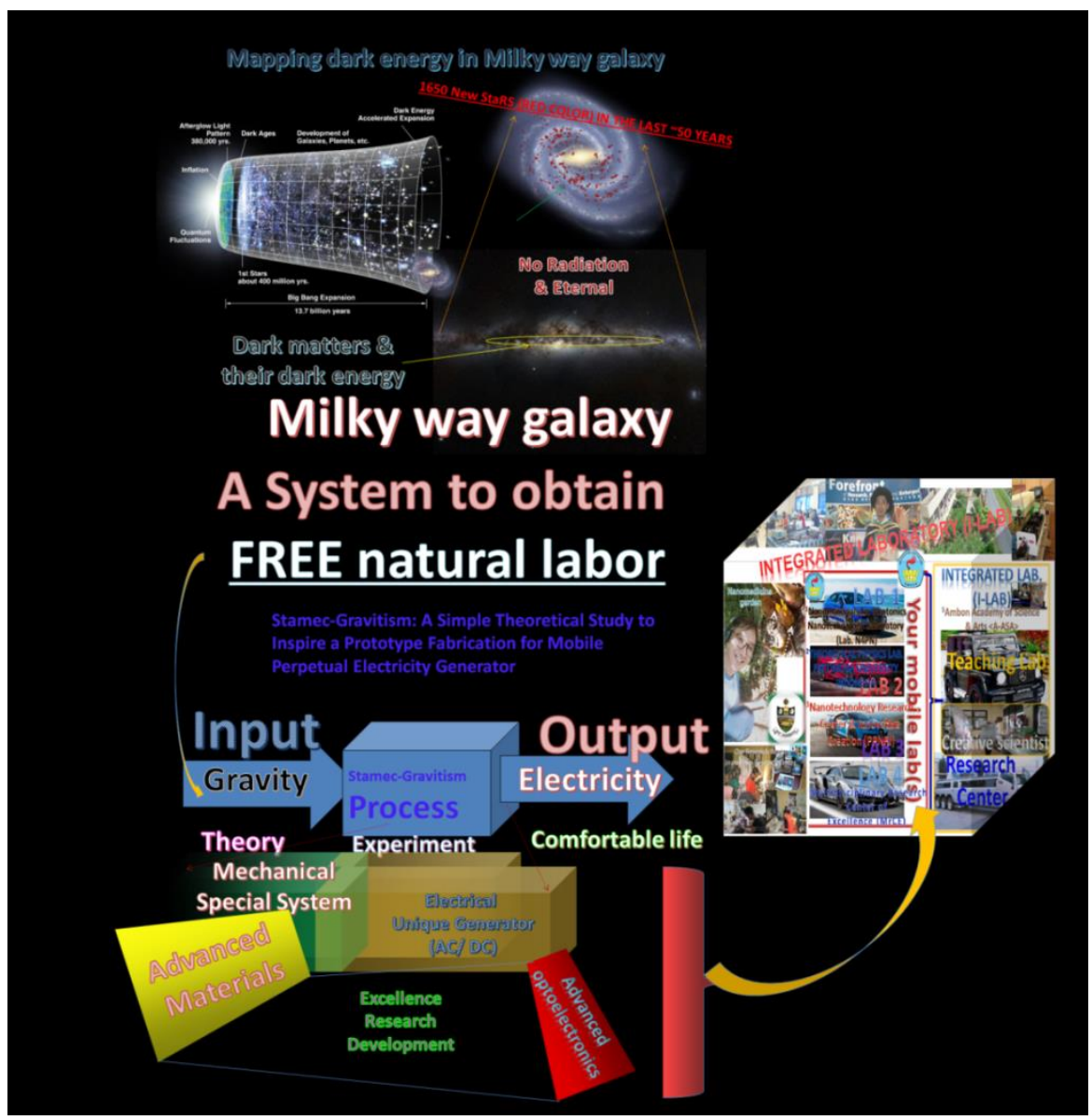

Figure 3. The main idea to employ eternal energy in universe by using gravity eternal power of its presence in universe. Some insets embedded in the illustration were courtesy according to excellent works of world scientists published in Nature (1869), UK and Science-AAAS (1848), USA. 


\section{Theoretical Method and Prototype \\ Design}

A theoretical model with its simplification was derived according to Fig. 4 consisted of 4 steps as follows: (1- I) Proposed theoretical prediction by linking all possible effective ways to solve the use of gravity as energy source, (2- II) and (3- III) are calculation procedures by employing the understanding among statistical mechanics, classical mechanics of rotation system and electricity and magnetism knowledge, as well as (4` IV), a design prototype of possible perpetual mobile device.

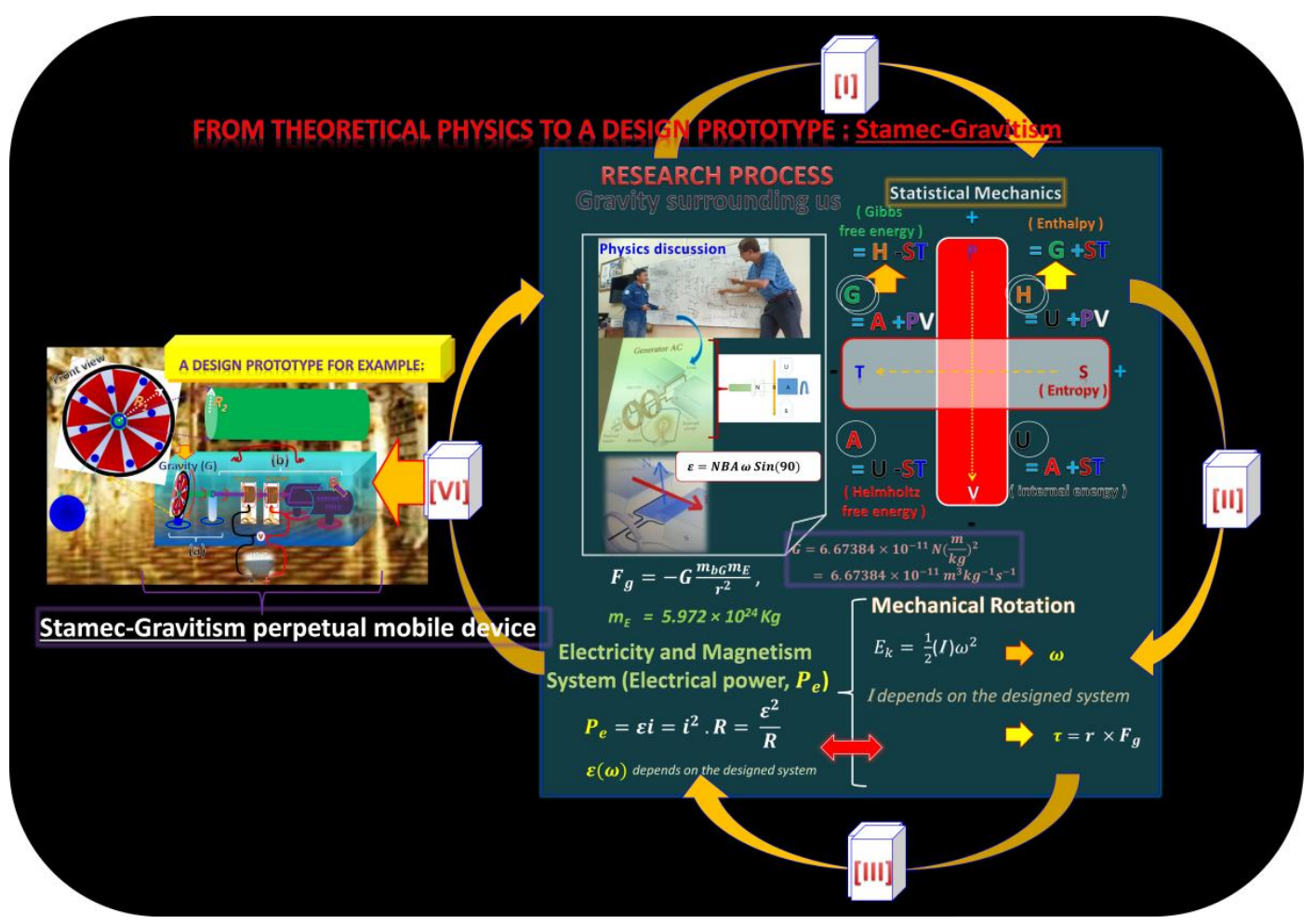

Figure 4. A simple prototype design of Stamec-Gravitism perpetual mobile device based on (1- I) proposed theoretical prediction, (2- II) and (3- III) calculation procedures, as well as (4• IV) a design prototype. 


\subsection{Proposed statistical mechanics theory for its links with gravity}

The inset in Fig. 4 shows detail theoretical physics of research process in extracting the use of gravity as electrical generator source. The starting point of simple mathematical physics of universal gravity is defined as follows

$$
F_{g}=-G \frac{m_{b G} m_{E}}{r^{2}}
$$

where $\boldsymbol{F}_{g}$ is gravity force $(\boldsymbol{N})$,

$\boldsymbol{G}$ is universal gravity constant

$\left(\mathrm{G}=6,67384 \times 10^{-11} \mathrm{~N}\left(\frac{\mathrm{m}}{\mathrm{kg}}\right)^{2}=6,67384 \times\right.$ $\left.10^{-11} \mathrm{~m}^{3} \mathrm{~kg}^{-1} \mathrm{~s}^{-2}\right), \boldsymbol{m}_{\boldsymbol{b} \boldsymbol{G}}$ is mass of energy generator $(K g), \boldsymbol{m}_{\boldsymbol{E}}$ is earth mass $(\sim 5.972 \times$ $10^{24} \mathrm{Kg}$ ), and $\boldsymbol{r}$ is the distance of the Stamec-Gravitism generator to the earth core $(\boldsymbol{m})$. In addition, the average earth radius $\left(\boldsymbol{r}_{\boldsymbol{E}}\right)$ is about $6371 \times 10^{3} \mathrm{~m}$.

The work associated with such gravity force as described in Eq. (1) can be written in the following Eq. (2):

$W_{b G}=F_{g} d s$,

where $\boldsymbol{W}_{\boldsymbol{b} \boldsymbol{G}}$ is Work (Joule), and $\boldsymbol{d} \boldsymbol{s} \sim \boldsymbol{d} \boldsymbol{r}$ is the position shift $(m)$. By integrating Eq. (2), we find out Eq. (3):

$W_{b G}=\int_{r_{i}}^{r_{f}}-G \frac{m_{b G} m_{E}}{r^{2}} d r$,

where $\boldsymbol{r}_{\boldsymbol{f}}$ is final distance of work $(m)$, and $\boldsymbol{r}_{\boldsymbol{i}}$ is the initial distance $(m)$. The result of Eq. (3) is shown in Eq. (4):

$W_{b G}=-G m_{b G} m_{E}\left[-\frac{1}{r_{f}}+\frac{1}{r_{i}}\right]$.

Equation (4) shows that the gravitational work happens when 2 masses are attracted into their center of mass proportional to the shift reversed of their position change.

In order to derive a relationship between the mass of energy generator energi $\left(\boldsymbol{m}_{b G}(S, H\right.$, T)) and temperature of system, Eq. (5) was used as a common thing in physics

$\boldsymbol{Q}=\boldsymbol{m}_{b G} \boldsymbol{C} \Delta \boldsymbol{T}$,

where $\boldsymbol{Q}$ is heat (Joule), $\boldsymbol{C}$ is specific heat $(\boldsymbol{J} / \mathbf{K g} . \boldsymbol{K})$, and $\Delta \boldsymbol{T}$ is temperature change $(K)$. By a special work of physical understanding, we obtain a definition of temperature in the case of isothermal (a physical system under a constant temperature) or $\boldsymbol{Q}=\boldsymbol{W}_{\boldsymbol{b} \boldsymbol{G}}$ due to the internal energy $\sim 0$ in conjunction with the theorem derived by a Germany scientist, Rudolf Clausius (1822 - 1888) in thermodynamics, $\boldsymbol{d Q}=\boldsymbol{T d} \boldsymbol{S}$ is the amount of heat absorbed during the transformation, where $\boldsymbol{d} \boldsymbol{S}$ is entropy change $(J / K)$ as depicted in Eq. (6):

$T=\frac{T_{f}-T_{i}}{L n T_{f}-\operatorname{Ln} T_{i}}=\frac{\Delta T}{\operatorname{Ln}\left(\frac{T_{f}}{T_{i}}\right)}$

The beauty definition of this hidden constant temperature for thousand of years in Eq. (6) is for the first time shown that temperature is actually a division between the temperature change $\left(\Delta T=\boldsymbol{T}_{\boldsymbol{f}}-\boldsymbol{T}_{\boldsymbol{i}}\right)$ and the logarithm $(\boldsymbol{L n})$ of $\left(\boldsymbol{T}_{\boldsymbol{f}} / \boldsymbol{T}_{\boldsymbol{i}}\right)$. For example: a measured constant temperature $\quad T=(34.10 \pm 0.05) C^{0} \quad$ is actually defined as 


$$
\begin{aligned}
\frac{T_{f}-T_{i}}{\operatorname{Ln} T_{f}-\operatorname{Ln} T_{i}} & =\frac{(34.15-34.05) C^{0}}{\operatorname{Ln}(34.15)-\operatorname{Ln}(34.05)} \\
& =\frac{0.10 C^{0}}{3.53076-3.52783} \\
& =\frac{0.10 C^{0}}{0.00293}=34.13 C^{0}
\end{aligned}
$$

Such simple discovery illustrates that the creator (GOD/ YaHWeH) is THE ONLY accurate inventor of His universe [58]. After such deep intellectual knowledge, we will then derive the interconnections among $\boldsymbol{m}_{\boldsymbol{b} \boldsymbol{G}}(\boldsymbol{S}, \boldsymbol{H}$, $\boldsymbol{T})$ with its entropy, $\boldsymbol{S}_{\boldsymbol{b G}}$ and specific heat, $\boldsymbol{C}_{\boldsymbol{b G}}$ under the influence of certain temperarture. Equation (7) shows an original thinking with 3 simple steps of mathematical work for such investigation.

Step 1. $\left[d S_{b G}\right]=\frac{d Q_{b G}}{T}=\frac{m_{b G} C_{b G} \mathrm{~d} T}{T}$,

step 2. $\int d S_{b G}=\int_{T_{i}}^{T_{f}} \frac{m_{b G} C_{b G} \mathrm{~d} T}{T}$,

step 3. $S_{b G}=m_{b G}\left[C_{b G}\left(\ln T_{f}-\ln T_{i}\right)\right]$, or

$$
m_{b G}=S_{b G} /\left[C_{b G}\left(\ln T_{f}-\ln T_{i}\right)\right]
$$

The result in Eq. (7) explains that entropy is created by a mass and its specific heat constant under a temperature change.

On the other hand, entalphy of the Stamec-Gravitism device is related to the total energy $\left(\boldsymbol{E}_{\boldsymbol{t} \text { tot }}\right)$ plus the work $\left(\boldsymbol{W}_{\boldsymbol{b G}}\right)$ as rewritten in Eq. (8).

$H_{b G}=E_{t o t}+W_{b G}$,

where $\boldsymbol{H}_{\boldsymbol{b} \boldsymbol{G}}$ is entalphy $(J)$ of designed rotor under gravity influence as shown in Fig. 4, and $\boldsymbol{E}_{\text {tot }}$ is the total energy $(J)$. Furthermore, from the total energy in the proposed Stamec-Gravitism device, $\boldsymbol{E}_{\text {tot }}=\boldsymbol{E}_{\boldsymbol{k}}+\boldsymbol{E}_{\boldsymbol{p}}$, the kinetic rotation energy can be extracted as shown in Eq. (9) in which the rotation inertia moment, $\boldsymbol{I}_{\boldsymbol{S G}}$ will be extracted later on in Sec. 2 according to the prototype design of the Stamec-Gravitism:

$E_{k}=\frac{1}{2} m_{b G} v_{g}^{2}$

where $v_{g}$ is the system velocity $(m / s)$. Finally such velocity of $\boldsymbol{v}_{\boldsymbol{g}}$ can be derived and written in its relationship with gravity, $\boldsymbol{G}$ as follows

$v_{g}=\int_{t_{i}}^{t_{f}}-G \frac{m_{E}}{r_{E}^{2}} d t==-G \frac{m_{E}}{r_{E}^{2}}\left(t_{f}-t_{i}\right)$,

where $\boldsymbol{t}_{\boldsymbol{f}}$ is final time $(s)$ of system, and $\boldsymbol{t}_{\boldsymbol{i}}$ is the initial time $(s)$.

By substituting Eq. (10) into Eq. (9), we find

$E_{k}=\frac{1}{2} m_{b G}\left(G \frac{m_{E}}{r_{E}^{2}}\right)^{2}\left[t_{f}-t_{i}\right]^{2}$.

Whereas the potential energy of $\boldsymbol{E}_{\boldsymbol{p}}$ in the

Stamec-Gravitism is defined as

$E_{p}=\boldsymbol{m}_{b G} \boldsymbol{g} r$

where $\boldsymbol{g}=d v / d t$ and $\boldsymbol{g}$ is the gravity constant in which the device was located, for example on earth, $g_{E} \sim 9.8 \mathrm{~m} / \mathrm{s}^{2}$. As a matter of facts, the relationship between $\boldsymbol{G}$ and $\boldsymbol{g}$ in earth location is found as follows

$g_{E}=-G \frac{m_{E}}{r_{E}^{2}}$.

The energy potential is finally obtained by substituting Eq. (13) into Eq. (12): 
$E_{p}=-G\left[m_{b G} m_{E}\right] \frac{r}{r_{E}^{2}}$.

Finally, the total energy as shown in Eq. (15) is the sum of Eq. (11) and Eq. (14).

$\boldsymbol{E}_{\text {tot }}=$

$\frac{1}{2} m_{b G}\left(G \frac{m_{E}}{r_{E}^{2}}\right)^{2}\left[t_{f}-t_{i}\right]^{2}-G\left[m_{b G} m_{E}\right] \frac{r}{r_{E}^{2}}$.

The total entalphy can be extracted by the summation of Eq. (15) and Eq. (4) in the following new form of Eq. (8):

$$
\begin{aligned}
H_{b G}=\frac{1}{2} m_{b G}\left(G \frac{m_{E}}{r_{E}^{2}}\right)^{2}\left[t_{f}-t_{i}\right]^{2} & -G\left[m_{b G} m_{E}\right]\left[\frac{r}{r_{E}^{2}}\right] \\
& -G\left[m_{b G} m_{E}\right]\left[-\frac{1}{r_{f}}+\frac{1}{r_{i}}\right] \\
= & \frac{1}{2} m_{b G}\left(G \frac{m_{E}}{r_{E}^{2}}\right)^{2}\left[t_{f}-t_{i}\right]^{2} \\
& -G\left[m_{b G} m_{E}\right]\left[\frac{r}{r_{E}^{2}}-\frac{1}{r_{f}}+\frac{1}{r_{i}}\right] \\
= & m_{b G}\left[\frac{1}{2}\left(G \frac{m_{E}}{r_{E}^{2}}\right)^{2}\left[t_{f}-t_{i}\right]^{2}-\right. \\
2 G & \left.m_{E}\left[\frac{r}{r_{E}^{2}}-\frac{1}{r_{f}}+\frac{1}{r_{i}}\right]\right] .
\end{aligned}
$$

Therefore, Eq. (16) explains the sum total of both energy and work in the Stamec-Gravitism apparatus. This entalphy has a close link with free energy Gibbs discovered by Josiah Willard Gibbs (1839-1903), temperature and entropy as described in the following free Gibbs energy:

$G_{G i b b s} \equiv H_{b G}-S_{b G} T$, where $\boldsymbol{G}_{\text {gibbs }}$ is free Gibbs energy $(J)$. Thus, by substituting Eq. (16), Eq. (6) and Eq. (7) into Eq.(17), one gets

$$
\begin{aligned}
G_{G i b b s} \equiv \frac{1}{2} m_{b G} & \left(G \frac{m_{E}}{r_{E}^{2}}\right)^{2}\left[t_{f}-t_{i}\right]^{2} \\
& -G\left[m_{b G} m_{E}\right]\left[\frac{r}{r_{E}^{2}}-\frac{1}{r_{f}}+\frac{1}{r_{i}}\right] \\
& -\left[T_{f}-T_{i}\right]\left[m_{b G} C_{b G}\right] .
\end{aligned}
$$

Equation (18) shows that the free Gibbs energy is actually enthalpy without the influence of entropy and temperature. Another free Helmholtz energy, $\boldsymbol{A}$ invented by Hermann Von Helmholtz (1821-1894) was a free potential energy, $\boldsymbol{U}$ excluded by the entropy, $S$ and temperature, $T$ and defined as follows

$\boldsymbol{A} \equiv \boldsymbol{U}-\boldsymbol{S}_{\boldsymbol{b G}} \boldsymbol{T}$,

where the free potential energy, $\boldsymbol{U}$ based on the first law of thermodynamics is the total sum of heat and work,

$\boldsymbol{U}=\boldsymbol{Q}+\boldsymbol{W}_{\boldsymbol{b G}}$

According to the first law of thermodynamics, the internal energy, $\Delta \boldsymbol{E}_{\boldsymbol{i n t}}=\boldsymbol{Q}-\boldsymbol{W}$. While we can prove that by understanding the free potential energy, such free Helmholtz energy, $\boldsymbol{A}$ equals to $\boldsymbol{W}_{\boldsymbol{b} \boldsymbol{G}}$ as shown in Eq. (21).

$$
\begin{gathered}
A \equiv Q+W_{b G}-S_{b G} T . \\
\sim m_{b G}\left[C_{b G}\right][\Delta T]-G m_{b G} m_{E}\left[-\frac{1}{r_{f}}+\frac{1}{r_{i}}\right] \\
-m_{b G}\left[C _ { b G } \left(\operatorname{Ln} T_{f}-\right.\right. \\
\left.\left.\operatorname{Ln} T_{i}\right)\right]\left[\frac{\Delta T}{\operatorname{Ln} T_{f}-\operatorname{Ln} T_{i}}\right]
\end{gathered}
$$




$$
\begin{aligned}
& \sim-\boldsymbol{G m}_{b G} \boldsymbol{m}_{E}\left[-\frac{1}{r_{f}}+\frac{1}{r_{i}}\right] \\
\mathbf{A} & \sim \boldsymbol{W}_{b G} .
\end{aligned}
$$

Equation (21) proves that a free Helmholtz energy is proportional to the work of a system.

\subsection{Proposed simple rotation mechanical theory for designing the} Stamec-Gravitism Apparatus

Based on Fig. 4, a simple rotation mechanical theory for such proposed design of Stamec-Gravitism apparatus was derived. The key point in such eternal rotor which moves continuously in an eternal time precisely is due to the presence of mysterious gravity with its infinite wavelength associated with no radiation impacts to surrounding environment of time and space. Moreover, such gravity can penetrate into atomic size system without changing the microscopic physics nature due to its extremely weak interaction. The only physical parameters that mostly influence gravity are an integrated temperature $(T)$, pressure $(p)$ and the interaction speed $\left(v_{i}\right)$ of two related objects in a system inside universe. Therefore, according to this deep understanding in gravity, we could propose an eternal rotor system that can generate electricity in a simple mobile electricity generator from one place to another place or from planet to another planet and so forth. We named it as Stamec-Gravitism perpetual mobile device for electricity generation. Starting from an ordinary design as depicted in the right inset part of Fig. 4, we chose two types of integrated cylindrical rotors with the small long-core and wide thin-shell radius of $\boldsymbol{R}_{2}$ and $\boldsymbol{R}_{1}$, respectively. Therefore, when such particular outer part in the rotor system was hit by small spherical solids due to unstoppable gravity force, we then can derive the total inertia moment, $\boldsymbol{I}_{\boldsymbol{S G}}$ in the following equation:

$I_{S G}=\frac{1}{2}\left[R_{1}^{2}\left(M_{1}+M_{2}\right)+M_{1} R_{2}^{2}\right]$,

where $\boldsymbol{I}_{\boldsymbol{S G}}$ is the enertia moment of Stamec-Gravitism perpetual mobile device Inersia $\left(\boldsymbol{k g ~ m ^ { 2 }}\right), M_{2}$ is the core cylinder mass $(\mathrm{kg})$, and $\boldsymbol{M}_{\boldsymbol{1}}$ is the shell cylinder mass $(\mathrm{kg})$. As a matter of fact, the kinetic energy of the rotor rotation can be calculated with the well known formula in Eq. (23).

$E_{\text {rot.k }}=\frac{1}{2} I_{S G} \omega^{2}$,

where $\omega$ is the angular speed or rotation velocity, $\omega=v / r \quad(r a d / s)$. This rotational kinetic energy is propotional to the thermodynamic kinetic energy, $\boldsymbol{E}_{\boldsymbol{k}}$ in Eq. (11). The angular speed is then extracted to be

$$
\begin{gathered}
\frac{1}{2} I_{S G} \omega^{2}=\frac{1}{2} m_{b G}\left(G \frac{m_{E}}{r_{E}^{2}}\right)^{2}\left[t_{f}-t_{i}\right]^{2} \\
\omega=\sqrt{\frac{\frac{1}{2} m_{b G}\left(G \frac{m_{E}}{r_{E}^{2}}\right)^{2}\left[t_{f}-t_{i}\right]^{2}}{\left[\frac{1}{2}\left[R_{1}^{2}\left(M_{1}+M_{2}\right)+M_{1} R_{2}^{2}\right]\right]}} \\
=\sqrt{\frac{m_{b G}\left(G \frac{m_{E}}{r_{E}^{2}}\right)^{2}\left[t_{f}-t_{i}\right]^{2}}{\left[R_{1}^{2}\left(M_{1}+M_{2}\right)+M_{1} R_{2}^{2}\right]}}
\end{gathered}
$$


In addition, the torsion of the rotation in Stamec-Gravitism perpetual mobile device is denined as $\boldsymbol{\tau}_{\boldsymbol{S G}}=\boldsymbol{r}_{\boldsymbol{t o t}} \times \boldsymbol{F}_{\boldsymbol{g}}$, where torsion is in $\mathrm{Nm}$ unit and $\boldsymbol{r}_{\text {tot }}$ is the total radius length in the Stamec-Gravitism. This torsion can be simplified as

$\boldsymbol{\tau}_{\boldsymbol{S G}}=\boldsymbol{r}_{\boldsymbol{t} \boldsymbol{t}} \boldsymbol{F}_{\boldsymbol{g}} \operatorname{Sin}(\boldsymbol{\omega} \boldsymbol{t})$

where $\boldsymbol{r}_{\text {tot }}=R_{1}$. By inserting Eq. (24) and Eq. (1) into Eq. (25), we obtain

$\tau_{S G}=-G \frac{r_{t o t} m_{b G} m_{E}}{r^{2}}$

$$
\operatorname{Sin}\left(\sqrt{\frac{m_{b G}\left(G \frac{m_{E}}{r_{E}^{2}}\right)^{2}\left[t_{f}-t_{i}\right]^{2}}{\left[R_{1}^{2}\left(M_{1}+M_{2}\right)+M_{1} R_{2}^{2}\right]} t}\right) .
$$

The angular momentum of such Stamec-Gravitism can thus be written as follows

$$
\begin{aligned}
L_{S G}=I_{S G} \omega & \\
L_{S G} & =\frac{1}{2}\left[R_{1}^{2}\left(M_{1}+M_{2}\right)\right. \\
& \left.+M_{1} R_{2}^{2}\right]\left(\sqrt{\frac{m_{b G}\left(G \frac{m_{E}}{r_{E}^{2}}\right)^{2}\left[t_{f}-t_{i}\right]^{2}}{\left[R_{1}^{2}\left(M_{1}+M_{2}\right)+M_{1} R_{2}^{2}\right]}}\right) .
\end{aligned}
$$

\section{Results and Discussion}

\subsection{Electrical power generated by perpetual} mechanical energy system in Stamec-Gravitism Device

In accordance with Fig, 4, there are two types of mechanical energy system and electrical system connected to perpetual Stamec-Gravitism rotor. Such common basic physics system is worked based on the eternal rotation of Stamec-Gravitism rotor which moves the electrical part and then generates electricity as the output. The mechnical power, $\boldsymbol{P}_{\boldsymbol{S G}}$ (Watt) of electricity can then be derived as follows

$$
\begin{aligned}
P_{S G} & =\tau_{S G} \boldsymbol{\omega}, \\
& =-G \frac{\left(R_{1} m_{b G} m_{E} \sqrt{\frac{m_{b G}\left(G \frac{m_{E}}{r_{E}^{E}}\right)^{2}\left[t_{f}-t_{i}\right]^{2}}{\left[R_{1}^{2}\left(M_{1}+M_{2}\right)+M_{1} R_{2}^{2}\right]}}\right) \operatorname{Sin}\left(\left(\sqrt{\frac{m_{b G}\left(G \frac{m_{E}}{r_{E}}\right)^{2}\left[t_{f}-t_{i}\right]^{2}}{\left[R_{1}^{2}\left(M_{1}+M_{2}\right)+M_{1} R_{2}^{2}\right]}}\right) t\right)}{r^{2}}
\end{aligned}
$$

Therefore, the perpetual mechanical energy, $\boldsymbol{E}_{\boldsymbol{m}}$ (Joule) $\sim \boldsymbol{P}_{\boldsymbol{S G}} \boldsymbol{t}$ in conjuction with the electricity part can be obtained as

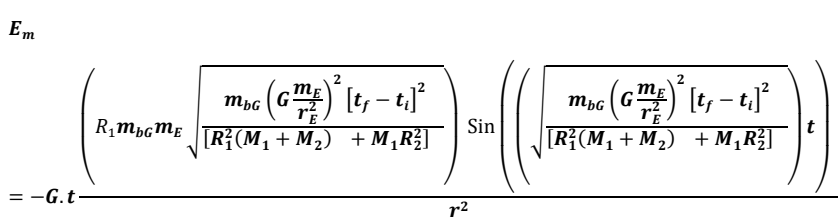


where $r$ is the distance $(m)$ of the Stamec-Gravitism generator to the earth core.

\subsection{The relationship between electromotive force $(e m f)$ and gravity energy}

The electrical device which is worked based on the power in perpetual mechanical energy designed rotor in Stamec-Gravitism device system in the inset of Fig. 4 was chosen according to Michael Faraday electricity understanding of electromotive force (emf) with electromagnetic oscillations induced electric field and magnetic flux . Such natural logic of thought obeys the following formula:

$\Phi=B \cdot A \cdot \operatorname{Cos}(\omega t)$,

where $\Phi$ is magnetic flux (weber), $B$ is magnetic field (Tesla) and $A$ is the area of electric field system $\left(\mathrm{m}^{2}\right)$. To derive the resulted voltage $(\varepsilon)$ in the Stamec-Gravitism device system, the use of both the first and second laws of Faraday is necessary stated that the magnetic change in a circuit wire causes the emf, and the emf in a close electrical circuit is propotional to the defferential flux velocity of magnetic field in certain time, respectively. Therefore, one obtains the following link:

$\varepsilon=-N \frac{d \Phi}{d t}$,

where $N$ is the number of turns per unit length of the solenoid in the electricity device embedded in the Stamec-Gravitism device. By substituting Eq. (30) into Eq. (31) and then differentiate it, the voltage $\varepsilon$ is simplified as follows

$$
\begin{aligned}
\varepsilon & =-N \frac{d(B \cdot A \cdot \operatorname{Cos} \omega t)}{d t} \\
& =N \cdot B \cdot A \cdot \omega \operatorname{Sin}(\omega t) .
\end{aligned}
$$

Finally, the detail solution of resulted $\varepsilon$ in the Stamec-Gravitism apparatus can be found by inserting Eq. (24) is the the following form:

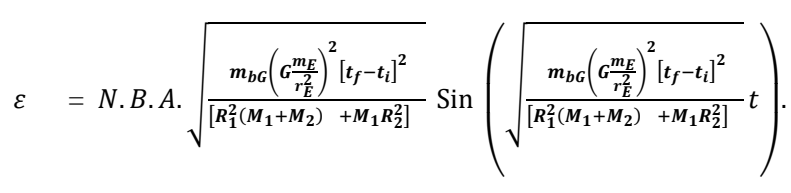

Moreover, the electricity current, $I=\frac{\varepsilon}{\mathrm{R}}$ in such Stamec-Gravitism apparatus is calculated as mentioned below:

$$
I=\frac{N . B . A . \sqrt{\frac{m_{b G}\left(G \frac{m_{E}}{r_{E}^{2}}\right)^{2}\left[t_{f}-t_{i}\right]^{2}}{\sqrt{\left.R_{1}^{2}\left(M_{1}+M_{2}\right)+M_{1} R_{2}^{2}\right]}} \operatorname{Sin}\left(\sqrt{\frac{m_{b G}\left(G \frac{m_{E}}{r_{E}^{2}}\right)^{2}\left[t_{f}-t_{i}\right]^{2}}{\left[R_{1}^{2}\left(M_{1}+M_{2}\right)+M_{1} R_{2}^{2}\right]}} t\right)}}{\mathrm{R}},
$$

where $\mathrm{R}$ here is the system resistant in unit of Ohm. The total electrical power, $P_{E}$ (Watt) produced by the apparatus is then obtained as

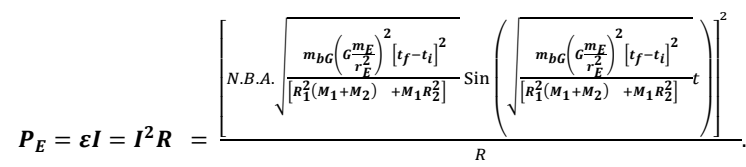

While the total electrical energy, $\boldsymbol{E}_{\boldsymbol{E}}=$ $\boldsymbol{P}_{\boldsymbol{E}} \boldsymbol{t}$ (Joule) is finally realized as Eq. (36).

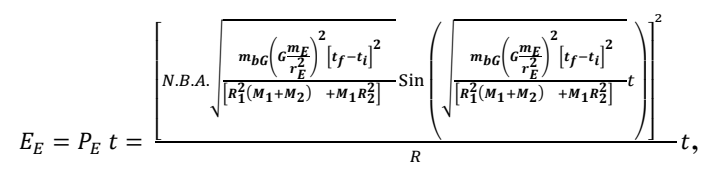




\subsection{Simple calculation with its simulation} to obtain the optimum size of mobile Stamec-Gravitism device

By simulating Eq. (35) and Eq. (36), we obtain the best physical parameters to harvest the output $\mathrm{AC}$ power $\sim 100 \mathrm{~W}$ with frequency $50 \mathrm{~Hz}$ as marked blue color and described in Table 1. The results show that this mobile Stamec-Gravitism device can be developed and applied in many different areas conveniently with a cheap price of mass productions.

Table 1. The best physical parameters for Stamec-Gravitism perpetual mobile device in harvesting output $\mathrm{AC}$ power $\sim 100 \mathrm{~W}$ with frequency $50 \mathrm{~Hz}$.

\begin{tabular}{|c|c|c|c|c|c|c|c|c|c|c|}
\hline $\begin{array}{l}M_{1} \\
(\mathrm{Kg})\end{array}$ & $\begin{array}{l}M_{2} \\
(\mathrm{Kg})\end{array}$ & $\begin{array}{l}R_{1} \\
\text { (m) }\end{array}$ & $\begin{array}{l}R_{2} \\
\text { (m) }\end{array}$ & $\begin{array}{c}\boldsymbol{\omega} \\
(H z)\end{array}$ & $\begin{array}{c}\boldsymbol{\Delta t} \\
(n s)\end{array}$ & $\begin{array}{c}\boldsymbol{t} \\
(s)\end{array}$ & $\begin{array}{c}\boldsymbol{\omega} \\
(\mathrm{m} / \mathrm{s})\end{array}$ & $\begin{array}{c}R \\
(\Omega)\end{array}$ & $\begin{array}{c}\boldsymbol{P} \\
(W)\end{array}$ & $\begin{array}{c}E \\
(J)\end{array}$ \\
\hline 3.9 & 1.1 & 0.3 & 0.02 & "50.16864 & 0.072 & 60 & 15.05059 & 0.55 & "99.61748 & "5977.04874 \\
\hline 4.0 & 1.0 & 0.3 & 0.02 & 50.16641 & 0.072 & 60 & 15.04992 & 1.00 & 40.05074 & 2403.04436 \\
\hline 4.1 & 0.9 & 0.3 & 0.02 & 50.16419 & 0.072 & 60 & 15.04926 & 2.00 & 12.30228 & 738.13673 \\
\hline 4.2 & 0.8 & 0.3 & 0.02 & 50.16197 & 0.072 & 60 & 15.04859 & 3.00 & 2.90846 & 174.50757 \\
\hline 4.3 & 0.7 & 0.3 & 0.02 & 50.15975 & 0.072 & 60 & 15.04793 & 5.00 & -1.461 & -87.66021 \\
\hline 4.4 & 0.6 & 0.3 & 0.02 & 50,15753 & 0.072 & 60 & 15.04726 & 7.00 & -3.31463 & -198.87753 \\
\hline 4.5 & 0.5 & 0.3 & 0.02 & 50.15531 & 0.072 & 60 & 15.04659 & 9.00 & -4.29834 & -257.90017 \\
\hline 4.6 & 0.4 & 0.3 & 0.02 & 50.15309 & 0.072 & 60 & 15.04593 & 10.0 & -5.34788 & -320.87303 \\
\hline 4.7 & 0.3 & 0.3 & 0.02 & 50.15087 & 0.072 & 60 & 15.04526 & 12.0 & -5.61018 & -336.61053 \\
\hline
\end{tabular}




\section{Conclusion}

Every important work is not that easy to solve and realize due to a must understanding deeply by incorporating the beauty of critical thinking with the multitasking impacts to others. Here, our summary in a picture is a proposed Stamec-Gravitism derived by understanding a simple theoretical study to inspire a prototype fabrication for mobile perpetual electricity generator has been in detail explained with the prototype design is shown in Fig. 5 as a part of integrated Fig. 4. In addition, we also provide an open insight of wide multitasking applications of such device in every actionable insight implementation of human being daily use of energy as described in Fig. 6. While the output energy can be adjusted higher than 100 watt $\mathrm{AC}$ of $\sim 50 \mathrm{~Hz}$ depending on the materials quality of Stamec-Gravitism and its modified mobile design.

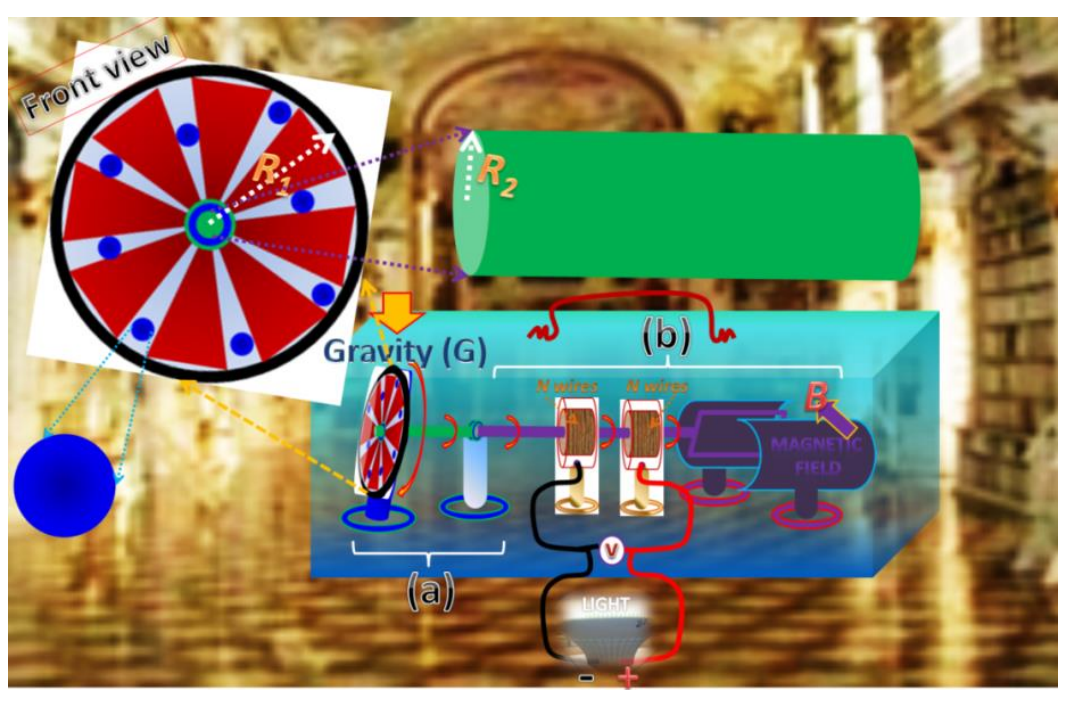

Figure 5. A proposed Stamec-Gravitism with free of radiation in order to mitigate any disasters on earth by generating mobile eternal electricity from one place to another place easily, from island to island conveniently, and from continent to continent handily as well as from a planet to another planet appropriately. 


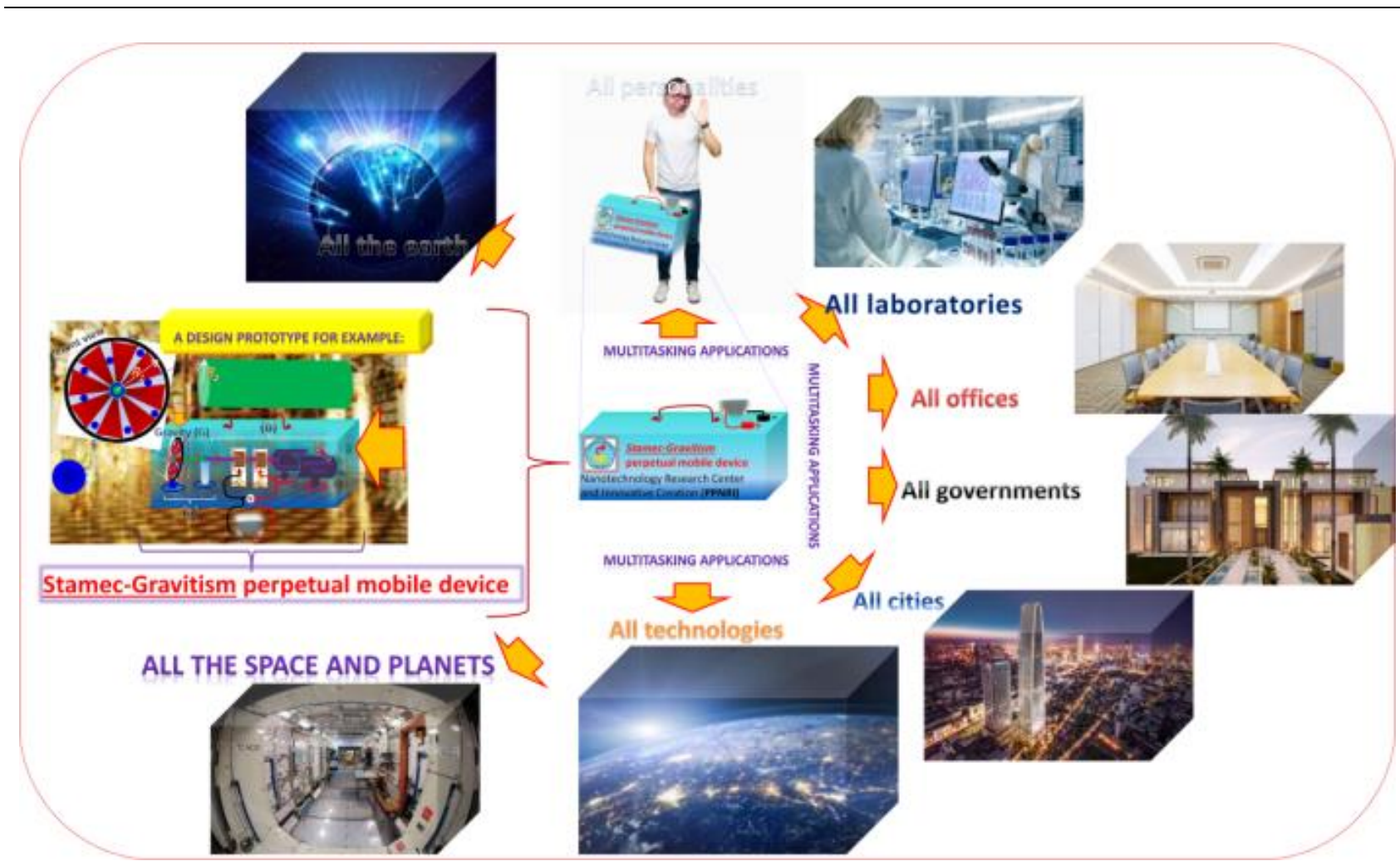

Figure 6. Proposed multitasking applications of

Stamec-Gravitism Mobile Perpetual

Electricity Generator in all daily uses energy of human being acticities.

\section{ACKNOWLEDGEMENT}

H.I.E and Y.P.I. thank to Prof. Dr. M.J. (Nus) Saptenno, one of the creative and innovative rector of Pattimura university due to his wide insight and open minded in supporting both research work and business since it was built on $23^{\text {rd }}$ April 1963. Part of this work was supported by a self-funding research grant of Nanotechnology Research Center and Innovative Creation (PPNRI-UNPATTI, URL: http://lppm.unpatti.ac.id/pusat-pnri) about new energy research.

\section{Additional information}

The authors declare no competing financial interest as well as any conflict of interest. 


\section{References}

[1]. H.I. Elim, E. Kembauw, R.H. Siahainenia, Jacobus S.A. Lamerkabel, A.M. Sahusilawane, S.W. Djoko, and B. Setha, Heavenly Small Islands Simple Technology \& Its Cultural Economy Impacts in Maluku, Indonesia: a New Proposed Multitasking Philosophy in Diversity (MPD), Science Nature 2(4), pp.192-207 (2019).

[2]. H.I. Elim, Nanomedicine with Its Multitasking Applications: A View for Better Health, IJHMCR 2(02), 353-357 (2017).

[3]. H.I. Elim, Physics of Multitasking Nanomedicine, International Journal of Health Medicine and Current Research (IJHMCR) 2(03), 509-519 (2017).

[4]. H. I. Elim, Theory, Implementation and the Nature of Truth (TIN) in Nanoscience, Nanotechnology, and Nanomedicine (NNN): From the Beginning of Universe to nm Scale Behavior, Kenkyu Journal of Nanotechnology \& Nanoscience 5, 33-36 (2019).

[5]. H. I. Elim, Multitasking Herbal Nanomedicine: A Frontier Report, Nanoscale Reports 2(1), 22-30 (2019).

[6]. H.I. Elim, The First 1000 Atoms in Healing Process: From Nanotechnology to Nanomedicine, IJHMCR 3(04), 1044-1046 (2018). Doi: 10.22301/ijhmcr.2528-3189.1044

[7]. H.I. Elim, Metode Fisika Eksperimen: Pelengkap Teori Fisika: "To be Perfect like The 1 Who Created Our Incredible Universe", Pattimura university press, Indonesia, 1st Edition, pp. 1-155 (2019). ISBN: 978-602-5943-05-8.

[8]. H.I. Elim, and A.L. Mapanawang, Electronics Physical System of Large Antioxidant Structure in Herbal Medicine based Zingiberaceae Fruit: Understanding and Application, Nanotechnology \& Applications 1(1), (2018). DOI: 10.33425/2639-9466.1004 (ISSN: 2639-9466)

[9]. H.I. Elim (Elim Heaven), A.L. Mapanawang, and M.V. Reddy, A Creative Proposal to Improve Woman and Child Health: from the Knowledge of Physical Nanoscience to Nanotechnology Implementation and Products, CPQ Women and Child Health 1(6), 01-11 (2019).

[10]. H.I. Elim, and A.L. Mapanawang, The attractive differences of two types of herbal medicine from zingiberaceae fruit (golobe Halmahera), IJHMCR 3(01), 799-806 (2018).

[11]. A.L. Mapanawang, and H.I. Elim, Unique Chemical Bonding Behavior of Love Herbal Medicine and Its Conjunction with

\author{
Chemotherapy Drug, J. Nanomedicine and \\ Nanotechnology 9(3), 1000503 (2018).
}

[12]. H.I. Elim, Scientific Breakthrough Based on Natural Creation: "1 Diamond with 7 Eyes", COJ Reviews and Research 1(1), pp. 1-4 (2018).

[13]. Hendry Izaac Elim (Elim Heaven), The Discovery of New Golobe and Its Amazing Healing System, Science Nature 2(1), pp. 66-70 (2019). DOI: https://doi.org/10.30598/SNVol2Iss1pp066-070y2019

[14]. A.L. Mapanawang, and H.I. Elim, Chemical Bonding Character of Love Herbal Medicine: A Prominent Medicine Candidate for Preventing HIV virus, Nanotechnology \& Applications 1(1), 1-4 (2018). DOI: 10.33425/2639-9466.1003 (ISSN: 2639-9466).

[15]. I.F. Seay and H.I. Elim, The Observation of Fast, Long Term, and Stable Performance of Toxic Absorption in Herbal Blessing Product Based on Galoba Maluku (Zingiberaceae Fruits), Science $\begin{array}{lllll}\text { Nature } & \text { 2(2), } & \text { pp. } & 122-127 & \text { (2019). }\end{array}$ https://doi.org/10.30598/SNVol2Iss2pp114-127y2019

[16]. H.I. Elim, Basic Universe of Molecular Electronics System (MES): Introduction and its Applications in Harvesting Daily Life, Science Nature 2(4), pp. 232-238 (2019).

[17]. H.I. Elim, From Molecular Electronics System (MES) to Advanced Nanotechnology: A Progress of Frontier Development, Nano Progress 2(4), pp. 7-11 (2020).

[18]. H.I. Elim, Is Your Brain Strong Enough to Solve Hard Problems? : Brain Vitamins as a Simple Example for Multitasking Nanotechnology Scientist, Science Nature 3(1), pp. 244-256 (2020).

[19]. H. v. Helmholtz, On the Thermodynamics of Chemical Processes, Berlin, (1891).

[20]. A. Einstein, Die Feldgleichungen der Gravitation, Königlich Preußische Akademie der Wissenschaften 6, pp. 844-847 (1915).

[21]. A. Einstein, Relativity the special and general theory, New York: Henry holt and company, (1920).

[22]. K. Huang, Statistical Mechanics, Canada: John Wiley \& Sons, (1976).

[23]. S. Weinberg, Gravitational and Cosmology: Principle and Aplication of The General Theory Relativity, USA: John Wiley \& Sons, (1972). 
[24]. J. W. Gibbs, A Method Of Geometrical Representation Of The Thermodynamic Properties Of Subtances By Means Of Surface, Traflsaclions of The Connecticut Academy vol. II, pp. 382-404 (1873).

[25]. I. Newton, Philosophice Naturalis Principia Mathematica, England, U.K.: global grey (2018), (1728).

[26]. O. Lodge, The Geometrisation of Physics, and its supposed Basis on the Michelson-Morley Experiment. Nature, p. 797, Feb 17 (1921).

[27]. D. L. Hotson, Dirac's Equation and the Sea of Negative Energy, Infinite Energy, issue 43, p. 4 (2002). It was noted by H. C. Dudley in Smithsonian 5 (7), October (1974), that, "Dirac advised a group of U.S. physicists to stop looking for more and more particles and direct their efforts elsewhere."

[28]. O. Lodge, University of Birmingham, March 25, 1911. Letters to the Editor, Nature 87, March 30 (1911).

[29]. M. Faraday, Experimental researches in electricity, Vol. 3, Dover Publications Inc., New York, pp 161-168 (1965).

[30]. G. B. Brown, Gravitational and Inertial Mass, American Journal of Physics 28, 475 (1960).

[31]. R. T. Cahill, The Einstein Postulates: 1905-2005-A Critical Review of the Evidence, "There is a detectable local frame of reference or 'space,' and the solar system has a large observed galactic velocity of some $420 \pm 30 \mathrm{~km} / \mathrm{s}$ in the direction $(\mathrm{RA}=5.2 \mathrm{hr}$, Dec $=-67 \mathrm{deg}$ ) through this space."

[32]. See for example, H. C. Dudley, Is there an ether? Industrial Research, pp. 43-6, Nov. 15 (1974).

[33]. S. Mitton, Reviewing The Milky Way by Stanley L. Jaki, New Scientist, p. 38, 5 July (1973).

[34]. Haliday, Resnick and J. Walker, Principle of Physics Ninth Edition International Student Version, USA: John Wiley \& Sons, (1989).

[35]. R. D'inverno, Introducing Einstein's relativity, Oxford: Oxford University Press, (1992).

[36]. A. K. T. Assis' and R. A. Clemente, The Ultimate Speed Implied by Theories of Weber's Type, Int. J. Theoretical Physics. 31(6), 1063-73 (1992).

[37]. G. E. Hinton and R. S. Zemel, "Autoencoders, minimum description length and Helmholtz free energy,," Advances in Neural Information Processing Systems, p. 3-10 (1994).
[38]. R. Sansbury, The Infinite or Finite Speed of Gravity and Light?, CP Institute, N.Y., p. 123 (1994).

[39]. P. J. E. Peebles and B. Ratra, The Cosmological Constant and Dark Energy, United Stated America: American Physics Society, (2003).

[40]. M. Wild, A. Ohmura and K. Makowski, Impact of global dimming and brightening on global warming, Geophysical Research letter 34 (4), (2007).

[41]. D. Tsaousis, Perpetual Motion Machines, Jestr, pp. $53-57$ (2008).

[42]. M. S. Hossen, M. T. Islam and S. Hossain, Design And Fabrication Of A Gravity Powered Light, in ICMERE2015-PI-254, Chittagong, Bangladesh (2015).

[43]. W. Thornhill, The Z-Pinch Morphology of Supernova 1987A and Electric Stars, IEEE Transactions on Plasma Science 35(4), pp. 832-844, August (2007).

[44]. Halton Arp, What has Science Come to?, Journal of Scientific Exploration 14(3), pp. 447-454 (2000).

[45]. L. Smolin, Einstein's Lonely Path, Discover 30/9/2004, "Special relativity was the result of 10 years of intellectual struggle, yet Einstein had convinced himself it was wrong within two years of publishing it. He had rejected his theory, even before most physicists had come to accept it." discovermagazine.com/2004/sep/einsteins-lonely-path/

[46]._S. J. Crothers, A Brief History of Black Holes, Progress in Physics 2, pp. 54-7, April (2006), See online at www.sjcrothers.plasmaresources.com/index.html "Einstein .did not understand the basic geometry of his gravitational field. Other theoreticians obtained the black hole from Einstein's equations by way of arguments that Einstein always objected to.

But Einstein was over-ruled by his less cautious colleagues, who also failed to understand the geometry of Einstein's gravitational field."

[47]. D. E. Scott, The Electric Sky: A Challenge to the Myths of Modern Astronomy, Mikamar Publishing, p. 73 (2006).

[48]. W. Paschelles, New Scientist, pp. 18-19, 13 January (2007).

[49]. Charles C. Gillispie, E. O. Wilson's Consilience: A Noble, Unifying Vision, Grandly Expressed, American Scientist, May-June (1998).

[50]. L. Li, J. Lin, N. Wu, S. Xie, C. Meng, Y. Zheng, X. Wang, and Y. Zhao, Review and outlook on the international renewable energy 
development, Energy and Built Environment, on 8 December (In press, 2020). https://doi.org/10.1016/j.enbenv.2020.12.002

[51].A. Peters, K.Y. Chung, and S. Chu, Measurement of gravitational acceleration by dropping atoms, Nature 400, pp. 849-852 (1999).

[52]._H.I. Elim, W. Ji, M.S. Dhoni, N. Venkatram, J. Yang, J.Y. Lee, Aspect-ratio Dependence of Optical Nonlinearities on Resonance with Longitudinal Surface Plasmon in Au Nanorods: Unique Character versus Common Behavior, Science Nature 1(1), pp. 001-007 (2018).

[53]. H.I. Elim, M.V.V. Reddy, R. Jose, A Frontier 2D Nanobattery:"Improving Challenges (Hotumese) and Development", Science Nature 2(2), pp. 114-121 (2019).

[54]. H.I. Elim, M. Rahman, W.S. Tutupoho, R.R. Latuconsina, A.A. Pattipeilohy, M.V. Reddy and J, Rajan, Flexible Thin Battery with Fast and Sensitive Voltage Control by a Simple Mechanical Bending: No Energy without Working, Science Nature 2(3), pp. 157-166 (2019).

[55]. D. Darbara, M.R. Anilkumard, V. Rajagopalanb, I. Bhattacharyac, H.I. Elim, T. Ramakrishnappaf, F.I. Ezema, R. Jose, M.V. Reddy, Studies on spinel cobaltites, $\mathrm{MCo}_{2} \mathrm{O}_{4}(\mathrm{M}=\mathrm{Mn}, \mathrm{Zn}, \mathrm{Fe}$, $\mathrm{Ni}$ and $\mathrm{Co}$ ) and their functional properties, Ceramics International 44, pp. 4630-4639 (2018).

[56]. K.P. Abhilash, P. Christopher Selvin, B. Nalini, Rajan Jose, Xia Hui, H. I. Elim, M.V. Reddy, Correlation study on temperature dependent conductivity and line profile along the LLTO/LFP-C cross section for all solid-state Lithium-ion batteries, Solid State Ionics 341, p. 115032 (2019).

[57]. R. Kunwar, F.I. Ezema, M. Harilal, S.G. Krishnan, B. Pal, I.I. Misnon, C. R. Mariappan, H. I. Elim, C-C. Yang, R. Jose, Pseudocapacitive Charge Storage in Thin Nanobelts, Advanced Fiber Materials 1, pp. 205-213 (2019). https://doi.org/10.1007/s42765-019-00015-w

[58]. Holy Bible, for example: Matthew 19:17; Mark 10:18; John 3:33.

[59]. H.I. Elim, Nonlinear Optics and The Frontier of Nanoscience and Nanotechnology, Pattimura University Press, Rajawali $\begin{array}{lllll}\text { printing, } 1 \text { st } & \text { Edition, pp. 1-144 (2019). ISBN: }\end{array}$ 978-602-61906-9-7.

[60]. M.J. Saptenno, S. Sisinaru, E. Ubwarin, W.A. Siahaya, and H.I. Elim, Customary Law Associated with Five Integrated Aspects in Developing Traditional Coastal and Marine Protections for
Improving Social People Life and Natural Products in Aru, Science Nature 2(2), pp. 105-113 (2019).

\section{Corresponding author CV:}

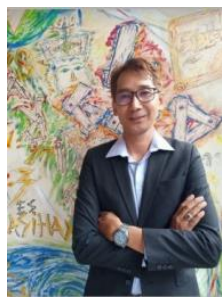

\section{Hendry Izaac Elim, Ph.D}

A simple physicist from a small island of Ambon, Indonesia with the educational background of both B.Sc. and M.Sc. in theoretical physics obtained at Gadjah Mada university (UGM) in 1995 and Bandung Institute of Technology (ITB) in 1999 as well as Ph.D (on 13rd December 2005) at NUS, Singapore in the field of physics of nanoscience and nanotechnology. Moreover, Dr. Elim experienced research fellow (type B), postdoctoral fellow and research assistant professor at NUS and Tohokun university in the interval time of 2014 up to 2012 Recently, Prof. Elim is an associate professor of physics at Pattimura university in the particular field of nanoscience, nanotechnology and nanomedicine. Prof. Elim has educated over 75 physics students in the last 7 years and published over 85 international papers with many multitasking discoveries in the whole of his physics career with the $\mathrm{h}$ index of 25 and citations from Web of Science over 2567

*ORCID ID of H. I. E.: $\quad$ 0000-0002-4272-7115

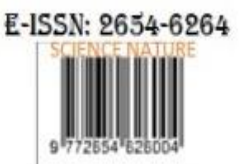

